Kalpa Publications in Civil Engineering
Volume 1, 2017, Pages 259-264
ICRISET2017. International Conference on Re-
search and Innovations in Science, Engineering
\&Technology. Selected papers in Civil Engineering $\quad$ Ka L po

\title{
Benchmarking: Green Aviation Transport System
}

\author{
Shaleha I. Vahora ${ }^{1}$, Prof. C. B. Mishra ${ }^{2}$ \\ M.Tech Transportation Engineering student, Department of Civil \\ Engineering, BVM Engineering College, V.V.Nagar, Anand, India. ${ }^{1}$ \\ Associate Professor, Department of Civil Engineering, BVM \\ Engineering College, V.V.Nagar, Anand, India. ${ }^{2}$
}

\begin{abstract}
Aviation is presently become the quickest developing ventures and additionally transportation modes in the world has reduced space for flying with passage of time having an impact on pollution level. The paper enlightens the concept of Green Transport and sustainable aviation system and benefits of it. Secondly study about the present scenario of Green aviation technology in world as well as in INDIA. Further study about the Vadodara International Airport, a first Green International Airport of Gujarat, and country`s second Green airport after Chandigarh`s terminal.
\end{abstract}

Keywords - Green aviation, sustainable development, Emission Reduction, Vadodara international airport

\section{INTRODUCTION}

Airports are framework that becomes an important part of the today's society and a vital part of the society's demand for mobility. Aviation industry is a fast growing section in the world. This causes issues with respect to sustainability. The future of airport planning is towards the sustainable airports. Airports are affecting the surrounding environments and the people who live in the zone. Therefore, it is critical for airports to be socially and environmentally capable. Numerous airports have started to build a sustainable environment. The Federal Aviation Administration (FAA) forecasts that the commercial aviation industry will continue growing an average of $3.6 \%$ per year over the next 20 years (FAA Forecast 2011-2031, p. 33). With a growing number of passengers, airports must continue to expand air traffic capacity and facilities. As this expansion of facilities takes place, aviation industry need to be more aware of environmentally-friendly practices which are available for airport use.

In order to minimize environmental impacts main focus on aircraft design and the design, construction, and operation of airports should be kept. Environmental training education and awareness is vital indeed in airports keeping in aspect the concept of green transport which has a significant impact on utilizing less energy and less $\mathrm{CO} 2$ and other unsafe toxins.

C.D. Modhera, G.J. Joshi, D. Soni, I.N. Patel, A.K. Verma, L.B. Zala, S.D. Dhiman, D.R. Bhatt, J.M. Rathod, B.C. Goradiya, M.S. Holia and D.K. Patel (eds.), ICRISET2017 (Kalpa Publications in Civil Engineering, vol. 1), pp. 259-264 


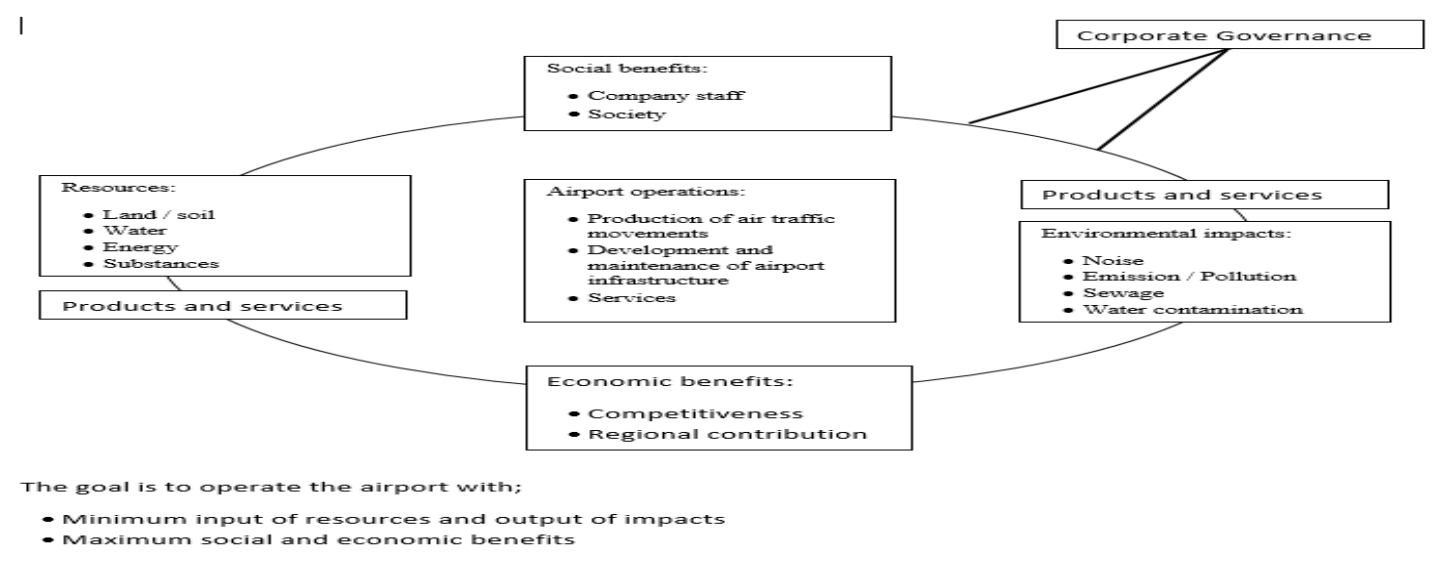

Figure 1: Benefits and causes of airport operation

\section{LITERATURE REVIEW}

Knowledge gained by undergoing literature study reveals the following facts:

A.N. Sarkar depicts the idea of development and manufacturing Green Aviation Transport concept and economical green marketing network.

Carbon Footprint of Indian Aviation 2013, First ever report by Directorate General of Civil Aviation (DGCA) which issued different rules for its partners so as to address the environmental issues particularly, one identified with emission from airplane.

H. Lee1, S. C. Olsen, D. J. Wuebbles, and D. Youn, made an attempt to evaluate the emission from aviation by developing the model and its adverse effect on the peripheral layer.

Jonas A Kerman, gives three Images of air transport on a sustainable way in 2050 are laid out. It is presumed that a refinement of the ordinary turbofan aircraft is most likely not adequate to reach even the less demanding target level, despite the fact that a $40 \%$ decrease of fuel power might be accomplished.

Maria MRAZOVA made an attempt to investigate the changes in climate due to $\mathrm{CO} 2$ emissions and a big challenge to the aviation's sustainable growth.

Organisation for Economic Co-operation and Development paper is on green growth and the future of aviation in which they explaining about the greenhouse gas emission in aviation sector and various initiatives to reduce it.

Arushi \&Stefan Drews provide a working paper on Avaition and environment which describe about the aviation growth and its impact on Environment. And also some emission reductions potential are also listed to reach to the Green aviation system.

\section{AVIATION AND ENVIRONMENT}

a) Growth of the industry:

With the rise in Indian economy, followed by liberalization, transformation is witnessed in last decade. The International Air Transport Association declared world passenger traffic results showing demand rose from $6.5 \%$ of 2015 compared 2015 (figure 2). India's aviation industry is elevated new highs and touching new skies, with the passenger growth hitting a record of $25 \%$ for the month of July, 2016.

\section{b) Emissions from Aviation Industry:}

The rising trend in growth of aviation traffic becomes a challenging mission considering environmental impact. Fig. 3 shows environmental effects of air transportation system. The principal 
emissions from aircraft engine comprise of $\mathrm{CO} 2$ and water vapour also includes $\mathrm{NOx}, \mathrm{CO}, \mathrm{SOx}, \mathrm{VOC}$, particulates and other trace components including HAPs. Contrails tend to warm the earth's surface by around $30 \%$ shielded with cirrus cloud.

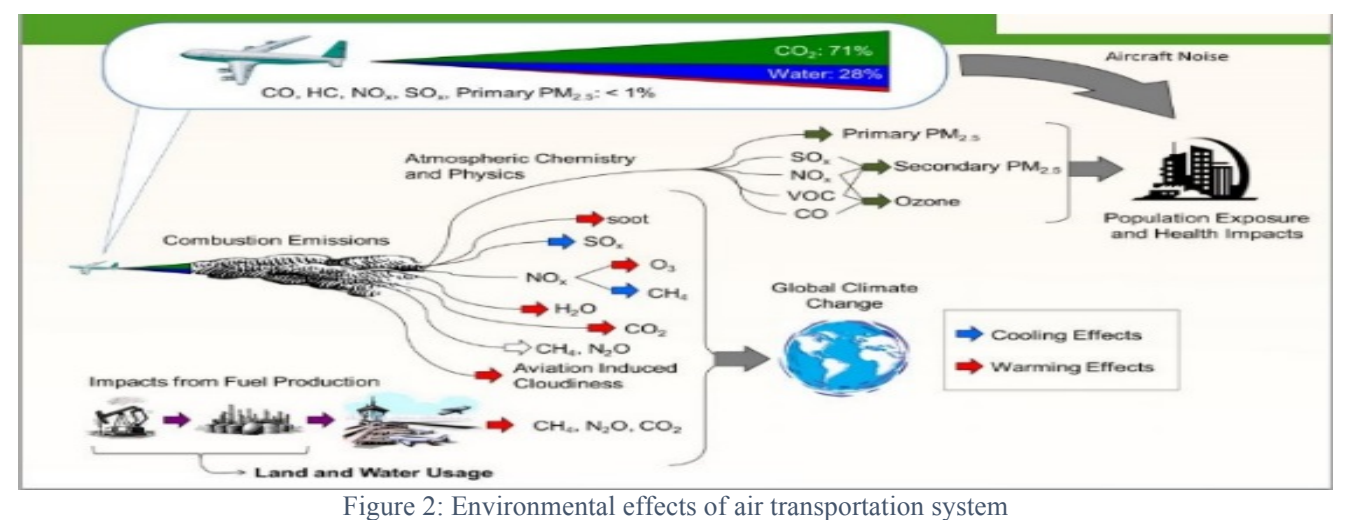

\section{c) Effect of emissions on the environment:}

Air pollutants have very adverse effect on environment. Effects due to the emission by aviation industry are Noise, air pollution, health effects and weather effects.

\section{SUSTAINABLE AND GREEN AIRPORT}

Sustainability: World Commission on Environment and Development defines it as "development that meets the needs of the present without compromising the ability of future generations to meet their own needs"

Way to a sustainable and green airport:

1. Technological Improvements

- Engine modification

- Advance aircraft design

- Alternative fuels

- Improve fuel efficiency

- Airport design based on green building

- Air Traffic Management (ATM)

- Structural efficiency

2. Sustainable Construction Management

3. Waste Management

4. Light-Emitting Diode Technology

5. Water Reclamation

6. Use of non-renewable energies like geothermal, solar energy, wind energy to generate electricity.

\section{a) India and Green Airport}

India has become the $9^{\text {th }}$ largest civil aviation market today. The Indian aviation sector witnessed 23\% domestic air passenger growth during January-August 2016, according to the data by Director General of Civil Aviation (DGCA). The total domestic passengers carried by the airlines during the same period was 64.4 million. The phenomenal growth in civil aviation is being led by the rise of low-cost carriers, competitive tariffs and quality service by India's extensive airport network. The Government of India is encouraging affordable flying in the country through various initiatives by the Ministry of Civil Aviation (MoCA). 


\section{b) Carbon Footprint for Civil Aviation Sector}

It is an important tool to understand the sources and magnitude of carbon emissions of any industry or- organization based on which future emission reduction policies/strategies can be formulated. The 50th DGCA conference held during October, 2012 had obtained significant recognition from the international aviation community regarding carbon footprint.

\section{c) GREEN AIRPORT AND TERMINALS IN INDIA:}

Green aviation technology is accepted in India from last 2-3 years. Till now there are three airport and terminals which we can say a green airport or a green terminal.

\section{- Chandigarh International airport:}

At the Chandigarh international airport in Mohali, inauguration of new terminal is done recently by Prime Minister Narendra Modi on September 11, 2015.It is "totally green" airport, the first ever airport in the country, and the way to build the airport in the country is potentially changed. It is 4-star GRIHA rating as it is environment-friendly green technology. Design of airport is done in such a way that it does not to enlighten the terminal during the daytime, possess low-heat absorb glass, Rooftop having $200 \mathrm{KW}$ sun based solar power plant which is sufficient to provide the maximum electricity needs of the terminal and also has Sewage treatment plant having a limit of 600 KLD having environment-friendly extended aeration technology.

\section{- Cochin International airport:}

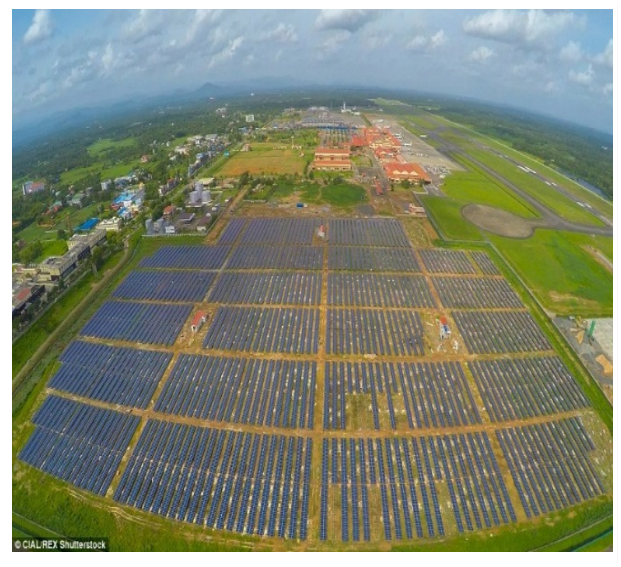

Cochin International airport, the nation's first air terminal worked under PPP has scripted another part in aviation history by turning into the first air terminal on the world that totally works on solar power. Inauguration of $12 \mathrm{MWp}$ solar power plant is done by Hon. Cheif Minister Mr. Oommen Chandy on eighteenth August 2015, including 46,150 solar panels laid crosswise over 45 acres of land close payload complex. Presently, Cochin airplane terminal's sunlight based power plant is creating 50,000 to 60,000 units of power for every day to be expended for all its operational function, which in fact make the air terminal completely power neutral.

Figure 3: Solar panel distribution in Cochin airport

- Vadodara International Airport:

Vadodara is now an international airport which is a domestic airport up to 22nd October 2016. It was inaugurated by Prime Minister Narendra Modi on 22 October 2016. The cost of the construction of new terminal building is of Rs. 160 Crores. After Cochi Airport, Vadodara International Airport is the second green airport of India. It is registered in the limca book of record for having longest single sheet measuring 164.4 metres.

The classy terminal has a way of 18,120 sq. meters by the whole of the flexibility to manage 700 passengers per hour which includes 500 domestic and 200 international. It has 18 checks in counters. Night parking facilities are also provided by AAI at the landing field which allow approximately nine A-320 / Boeing 737-800 aircraft to park and thus decreasing the work load on the major airport such as Mumbai and Ahmedabad and become economical for the air company. 


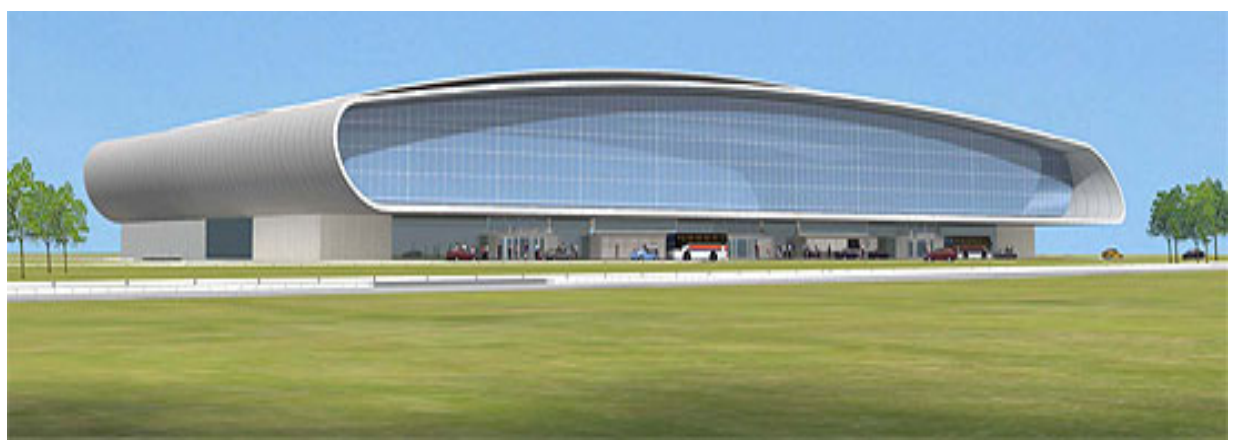

Figure 4: Vadodara International Airport

\section{FEATURES:}

1. Roof top of the airport terminal is constructed by using a sheet of length 164.4 meters, making a world record of having a single longest sheet which has been already registered in Limca Book of Records.

2. As a green inventiveness, decoration at the VIP and CIP lounge are completed by sugarcane pulp.

3. UNIQUE STRUTURE: The new terminal of Vadodara has a unique steel structure based entirely on the Green building and advanced building management system.

- Terminal steel structure is constructed in such a way that it form a column-free building and rises to form open and light structure.

- Column-free roof structure provides open and public spaces for hold room and public concourse.

- Terminal design mainly includes the repetition of the basic unit due to this there is an increase in efficiency for engineering and construction.

- Truss structure supporting the roof from East to west is rest on the shear walls and forces generated at the base is directly transferred to the foundation.

- Construction of departures level floor is done using

- Post-tensioned and conventionally reinforced concrete.

- In order to provide maximum structural competence, girders are post-tensioned which insure the limitation in overall depth of the structural casing. Construction methods with conventional reinforced concrete are used to design the beams and slabs enclosing into these girders.

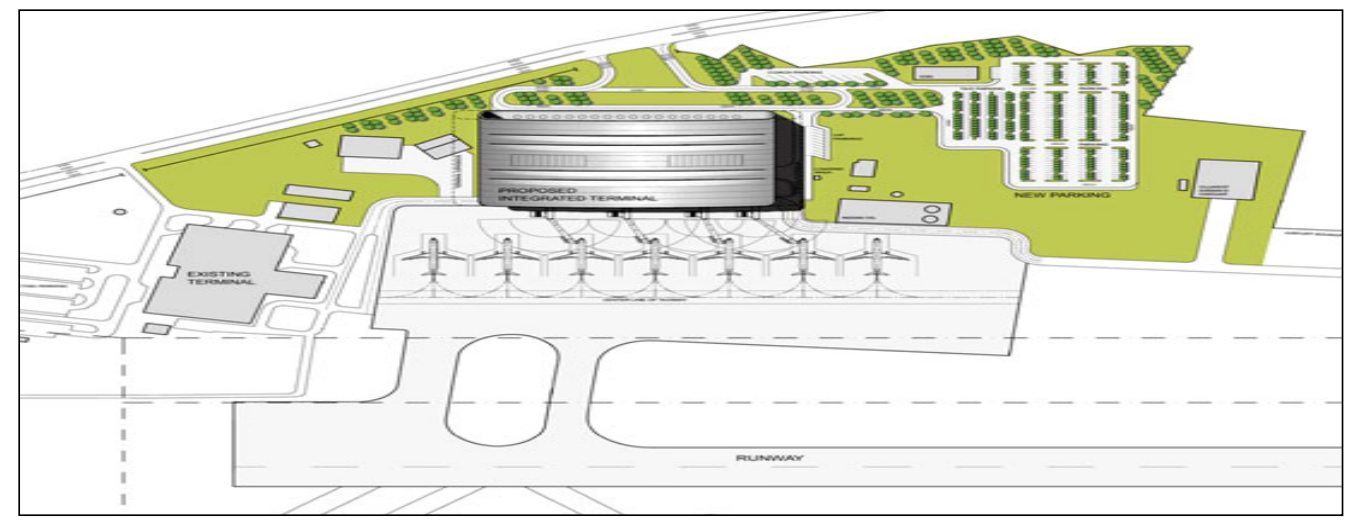

Figure 5: Top view of Vadodara International Airport 


\section{PARKING FACILITY:}

- Parking facilities are provided in new terminal for almost 230 cars, 10 coaches and 100 taxis.

- Night parking facilities are also provided at the landing field which allow approximately nine A320 / Boeing 737-800 aircraft to park and thus decreasing the work load of the major airport such as Mumbai and Ahmedabad and become economical for the air company.

\section{ENERGY-EFFICIENT GLASS:}

- This terminal possesses reflective solar control glass to cut excessive heat while optimizing light transmission.

- Saint-Gobain Infinity has once again been called on to demonstrate its prowess in providing sustainable glazing options. $6000 \mathrm{sqm}$ of SGG COOL-LITE was supplied to ensure advanced solar control across the terminal. A heat reflective glass, SGG COOL-LITE cuts down excessive heat and optimizes light transmission. The result: reduced dependence on air-conditioning and artificial lighting.

6. Sweeping roof, motivated via plane bodies and wings, traverse the whole length of the terminal with one continuous, streamlined metal skin. A stretched portion overhangs the arrival area, punctuated with circular openings that give daylight and regular ventilation.

7. Enhance the visitor experience:

- Soaring ceiling

- Garden n lawns

- Sound of flowing water, Stepped pool is provided near the visitor's concourse and baggage claim.

8. Airport is built on the standard of green foundation utilizing blocks of fly ash.

It will be utilized for direct international flights for neighboring nations. A non-stop flight for the US or the UK won't be conceivable as the length of the current runway is insufficient for huge airplane. Currently 10 flights operate every day from Vadodara.

\section{CONCLUSION}

The result of the review shows that the worldwide avionics industry is focusing more toward natural, particularly when considered in light of the anticipated development in flight activity. The aggregate endeavors in airplane plan and assembling; elective and greener fuel sources, for example, energy components and bio-fuels; efficient engines; course advancement and system improvement; proficient air movement administration; coercive authoritative arrangements; and positive financial measures and this would be advantageous to Indian society.

\section{REFERENCES}

[1] A. N. Sarkar, "Evolving Green Aviation Transport System: A Holistic Approach to Sustainable Green Market Development”, International Business \& Research, Asia-Pacific Institute of Management, New Delhi, India.

[2] Air Transport Action Group (ATAG, 2010), "Beginner’s Guide to Aviation Efficiency," Switzerland, 2010.

[3] B. Saynor, A. Bauen and M. Leach, "The Potential for Renewable Energy Sources in Aviation," Imperial College, London, 07 August 2003.

[4] Directorate General of Civil Aviation India,"Carbon footprint of Indian Aviation 2013", Technical Centre, New Delh, 2013.

[5] Green Transport, "Resource Optimization in the Road Sector in PRC Main Report—Asian Development Bank and Ministry of Transport, People's Republic of China Collaborative Project," Asian Development Bank, 2009.

[6] International Civil Aviation Organization (ICAO) Environmental Report 2016: aviation and climate change,1 Aug,2016.

[7] IPCC Special Report, “Aviation and the Global Atmosphere,"IPCC Working Groups I and III in Collaboration with the Scientific Assessment Panel to the Montreal Protocol, 1999.

[8] J. Akermann, "Sustainable Air Transport—on Track in 2050," Transportation Research Part D: Transport and Environment,Volume 10, Issue 2, March 2005, Pages 111-126.

[9] Leonie Tiben, Gradution Thesis,"Sustainable Airport Solutions" NHL University of Applied Sciences, June 5, 2012.

[10] Moharamnejad and Azarkamand, "Implementation of Green Productivity Management in Airline Industry," International Journal of Environmental Science and Technology, Vol. 4, No. 1, 2007. 